\title{
Lawrence H. Cohn, MD-our mentor in cardiac surgery
}

\author{
Vakhtang Tchantchaleishvili ${ }^{1}$, Taufiek Konrad Rajab ${ }^{2}$, Prem S. Shekar ${ }^{2}$ \\ ${ }^{1}$ Department of Cardiovascular Surgery, Mayo Clinic, Rochester, Minnesota, USA; ${ }^{2}$ Division of Cardiac Surgery, Brigham and Women's Hospital, \\ Harvard Medical School, Boston, Massachusetts, USA \\ Correspondence to: Prem S. Shekar, MD. Division of Cardiac Surgery, Brigham and Women's Hospital, 75 Francis Street, Boston, MA 02115, USA. \\ Email: PSHEKAR@partners.org.
}

Submitted Oct 15, 2015. Accepted for publication Dec 02, 2016.

doi: 10.21037/acs.2017.04.01

View this article at: http://dx.doi.org/10.21037/acs.2017.04.01

We respectfully write this tribute to our mentor, Dr. Lawrence H. Cohn, the Emeritus Virginia and James Hubbard Professor of Cardiac Surgery at Harvard Medical School and Brigham and Women's Hospital. Were it not for his untimely demise, he would have been the guest editor of this issue (Figure 1).

Dr. Cohn was born on March 11, 1937, in San Francisco, California, and grew up in the Bay Area. Dr. Cohn excelled academically at Lowell High School and proceeded to a baccalaureate with honors from the University of California at Berkeley in 1958. He graduated from Stanford University School of Medicine (Alpha Omega Alpha Honor Medical Society) in 1962, which marked the beginning of his extraordinary career as a surgeon, scientist and teacher.

At medical school, Dr. Norman Shumway inspired him to be a cardiac surgeon. Dr. Cohn was the first medical student at Stanford to palpate the inside of the heart with his finger during a closed mitral commissurotomy. The resulting spell on Dr. Cohn was so powerful that he would spend entire weeks on Dr. Shumway's service without ever leaving the hospital. Luckily for Dr. Cohn, his wife Roberta would visit him in the hospital for meals.

Following medical school, Dr. Cohn entered the general surgical residency on the Harvard Surgical Service at Boston City Hospital. Within his general surgery training, Dr. Cohn spent two years at the National Institutes of Health (NIH), where Dr. Andrew Glenn Morrow and Dr. Eugene Braunwald taught him how to become an academic cardiac surgeon. During this time, Dr. Cohn studied cardiac valvular physiology and also honed his surgical skills by performing a large number of animal operations. In addition, he found time to participate in cardiac catheterizations at the NIH cardiac catheterization

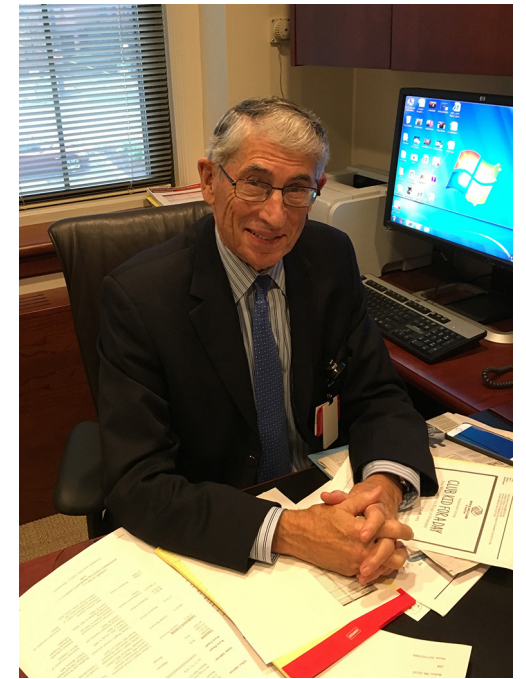

Figure 1 Dr. Lawrence Cohn in his office at Brigham and Women's Hospital while working on the Tricuspid Valve Surgery issue of Annals of Cardiothoracic Surgery, October 13th, 2015.

laboratory. He then returned to California to complete his general surgery training at the University of California, San Francisco. Dr. Cohn entered the cardiothoracic surgery training program at his alma mater, Stanford University, which at that time had the best outcomes in cardiac surgery in the world.

Following completion of his cardiothoracic surgery training in 1971, Dr. Cohn was immediately recruited to the Peter Bent Brigham Hospital (now Brigham and Women's Hospital), where he remained on staff until his passing. Dr. Cohn's mentors at the Brigham were Dr. John Collins, Dr. Francis Moore, Sr, and Dr. John Mannick. By 1980 he was a full professor at Harvard Medical School. In 1987, 
he was appointed chief of the division and director of the Cardiothoracic Surgery Residency Program, and in 2000, he received the first endowed Chair in Cardiac Surgery. Dr. Cohn's outstanding achievements in the medical field led to many awards: a Doctor Honoris Causa from the University of Paris in 1992, the Paul Dudley White Award in 2005, the highest honor given by the American Heart Association, and the Surgery Mentoring Award from the American Heart Association's (AHA) Council on Cardiovascular Surgery and Anesthesia in 2014.

Dr. Cohn's influential contributions to the field include a large number of new surgical techniques. Importantly, Dr. Cohn popularized mitral valve repair by developing simplified techniques that avoid the need for posterior leaflet advancement flaps. Dr. Cohn was also an early advocate of the hemisternotomy approach for minimally invasive valve surgery. He performed close to 12,000 cardiac surgical operations on patients from all corners of the world. He published over 550 peer reviewed papers and over a dozen textbooks, including the most referenced textbook in the field, Cardiac Surgery in the Adult. Dr. Cohn was the founding Editor of Fournal of Cardiac Surgery, Editor of the Fournal of Thoracic and Cardiovascular Surgery, Editor of Operative Techniques in Cardiac and Thoracic Surgery, and Editor of Modern Techniques in Surgery. He was also president of the American Association for Thoracic Surgery, president of the American College of Chest Physicians, president of the Thoracic Surgery Foundation for Research and Education, chair of the Board of Regents of the National Library of Medicine, and examination chair of the American Board of Thoracic Surgery. Dr. Cohn trained over 200 residents and fellows, of whom approximately 30

Cite this article as: Tchantchaleishvili V, Rajab TK, Shekar PS. Lawrence H. Cohn, MD_our mentor in cardiac surgery. Ann Cardiothorac Surg 2017;6(3):191-192. doi: 10.21037/ acs.2017.04.01 went on to become chiefs of their own division or chairs of their own departments.

In 2008, during his grand rounds lecture, Dr. Eugene Braunwald compared his impression of Dr. Cohn's operating techniques to a master playing a Stradivarius violin. The authors themselves were privileged to witness Dr. Cohn in the operating room. This inspiration has been guiding us since then, perhaps similar to Dr. Shumway's "spell" which was cast upon Dr. Cohn.

Dr. Cohn is survived by his wife Roberta, daughters Leslie Bernstein and Jennifer Cohn, and grandchildren Carly, Rachel, and Cameron. Dr. Cohn also had a deep love and lifelong passion for golf and tennis. He established the Lawrence H. Cohn, MD Library at Brigham and Women's Hospital and contributed in many ways to the global health forum at the Harvard T.H. Chan School of Public Health. Dr. Cohn also supported many Boston institutions including Museum of Fine Arts, The Boys and Girls Club of Boston, and The Boston Symphony Orchestra.

Dr. Cohn will continue to exemplify the ideals of the surgeon-scientist and serve as our role model as perfect technician, consummate investigator, dedicated teacher, and quintessential leader.

\section{Acknowledgements}

None.

\section{Footnote}

Conflicts of Interest: The authors have no conflicts of interest to declare. 